\title{
Isolamento de Chaetomium spp. em lesões subcutâneas de um cão: relato de caso
}

\author{
[Isolation of Chaetomium spp. on subcutaneous lesions of a dog: case report] \\ C.A.S.B. Braga ${ }^{1}$, A.F. Romani ${ }^{1}$, F.S. Balestra ${ }^{2}$, E.L. Ribeiro ${ }^{1}$ \\ ${ }^{1}$ Universidade Federal de Goiás - Goiânia - Goiás \\ ${ }^{2}$ Médico veterinário autônomo
}

\begin{abstract}
RESUMO
Caracterizou-se clinicamente a infecção pelo Chaetomium spp. em um cão, e descreveu-se seu isolamento e identificação. Ao exame dermatológico foram observadas pápulas nas orelhas, no tronco lateral e nos membros pélvicos. Ao rompimento de uma dessas pápulas, fluiu um líquido serosanguinolento com consequente úlcera no local. Foi colhido material para isolamento micológico, por meio de raspado das pápulas da orelha e da cauda. O diagnóstico foi micose subcutânea por Chaetomium spp.
\end{abstract}

Palavras-chave: cão, micose subcutânea, Chaetomium spp

\begin{abstract}
This work aimed to clinically characterize the infection by Chaetomium spp. in a dog, as well as describe its isolation and identification. Upon dermatological exam, papules on ears, lateral trunk and pelvic members were noticed. After the disruption of these papules there was serosanguineous secretion flowed by consequent ulcer in the region. Material for mycological isolation was picked, and a scraping of papules from ear and tail was done. The diagnosis was subcutaneous mycosis caused by Chaetomium spp.
\end{abstract}

Keywords: subcutaneous mycosis, dog, Chaetomium spp

\section{INTRODUÇÃO}

As micoses são doenças causadas por fungos, em seu grande número oportunísticas, e que podem ficar restritas ao tecido cutâneo ou se tornarem sistêmicas. Dentre as micoses mais comuns estão as subcutâneas, que são infecções causadas por um grupo diversificado de fungos que acometem o homem e os animais. Em sua maioria, os fungos envolvidos são sapróbios habituais do solo e de vegetais em decomposição (Almeida, 2007).

As lesões provocadas pelo Chaetomium spp. em humanos são caracterizadas como ulcerosas e papulosas (Lacaz et al., 2002). Não foi encontrada na literatura consultada relato em animais. O Chaetomium é um ascomiceto, que produz esporos em esporângios específicos, chamados ascomas, que são corpos de

Recebido em 13 de abril de 2011

Aceito em 13 de setembro de 2012

E-mail: carlaafonso@bol.com.br frutificação (Rodrigues-Heerklotz e Pfenning, 2007).

O crescimento é rápido, e a colônia possui textura cotonosa e superfície de cor branca inicialmente, tornando-se cinza a verde-oliva com reverso que vai do castanho ao preto. As hifas são septadas, hialinas a castanho pálido, o peritécio possui cor castanha a preta, sendo largos, frágeis, globosos ou em forma de barril e possuem filamentos em forma de seta, longos, ondulados, eretos ou helicoidais em toda a superfície (Rodrigues-Heerklotz e Pfenning, 2007). O objetivo deste trabalho foi caracterizar clinicamente a infecção pelo Chaetomium spp. em um cão, bem como descrever seu isolamento e identificação. 


\section{CASUÍSTICA}

Um cão da raça Pit Bull, com dois anos de idade, foi levado ao Ambulatório Veterinário Escola por apresentar várias lesões dermatológicas localizadas na orelha, na cauda e nos membros pélvicos. Durante anamnese, o proprietário informou que se tratava de um cão errante que fora adotado um mês antes. Inicialmente havia alopecia na ponta das duas orelhas e na extremidade da cauda. Essas lesões agravaram-se e surgiram pápulas subcutâneas disseminadas. Como o animal já havia sido recolhido com as lesões, não foi possível estimar quando se iniciaram os sinais. $\mathrm{O}$ animal apresentava-se magro e alimentava-se de comida caseira.

No exame físico geral, verificou-se estado geral bom, sem alterações dignas de nota. Ao exame dermatológico, foram observadas pápulas nas orelhas (Fig. 1), no tronco lateral e nos membros pélvicos. Ao rompimento de uma dessas pápulas, verificou-se que fluía líquido serosanguinolento com consequente úlcera no local (Fig. 2).

Foi colhido material para isolamento micológico, tendo sido feito um raspado das pápulas da orelha e da cauda com lâmina de bisturi, o qual foi colocado em placa de Petri esterilizada. Com um suabe foi colhido líquido que fluía da pápula rompida no membro pélvico esquerdo. As amostras, enviadas ao laboratório de microbiologia, foram semeados em Ágar Sabouraud dextrose, suplementado com $0,5 \%$ de cloranfenicol e incubados em temperatura ambiente por quatro dias. Após o crescimento da colônia, foi realizado o exame microscópico com auxílio de fita adesiva transparente colocada sobre a colônia e logo em seguida fixada em lâmina contendo duas gotas de algodão azul de lactofenol. A lâmina foi então visualizada ao microscópio óptico com aumentos de 10 e 40x.

Com três dias de observação, verificou-se o crescimento de três colônias nos pontos de cultivo do raspado de pele e de uma colônia no cultivo do espécime clínico oriundo da úlcera. As colônias foram semelhantes na sua estrutura macroscópica: apresentavam textura cotonosa com o anverso branco acinzentado (Fig. 3) e o reverso castanho claro/amarelo com bordas esbranquiçadas (Fig. 4). Ao exame microscópico, observaram-se hifas hialinas e grande quantidade de peritécio de cor negra, globoso, circundado por filamentos em forma de setas rígidas e presença de vários ascósporos castanhos em forma de limão (Fig. 5 e 6). As características observadas na descrição morfocolonial e microscópica foram iguais às descritas por Sutton (2007), permitindo a classificação do fungo como Chaetomium spp.

\section{DISCUSSÃO E CONCLUSÕES}

O Chaetomium spp. causou lesão cutânea e subcutânea, alopecia seguida por pápulas subcutâneas. As lesões induzidas pelo Chaetomium spp. no homem e descritas por Lacaz et al. (2002) foram semelhantes às observadas no presente caso.

Parte da literatura consultada mostra a característica oportunística do fungo, principalmente em pacientes imunocomprometidos, como relatado por Al-Aidaroos et al. (2007). Para Aspiroz et al. (2007), espécies fúngicas do gênero Chaetomium usualmente colonizam restos de plantas contendo celulose, mas em raras ocasiões podem causar micoses oportunísticas e infecções cutâneas em indivíduos saudáveis. Como o cão deste relato era errante, não havia histórico de saúde do mesmo. Ressalta-se que, no cultivo aqui descrito, foram isoladas apenas colônias de Chaetomium spp. dos espécimes clínicos do raspado e do líquido da úlcera, confirmando a etiologia das lesões dermatológicas descritas. A micose subcutânea em cão pode também ser causada pelo Chaetomium spp. com características clínicas semelhantes às descritas em seres humanos. 


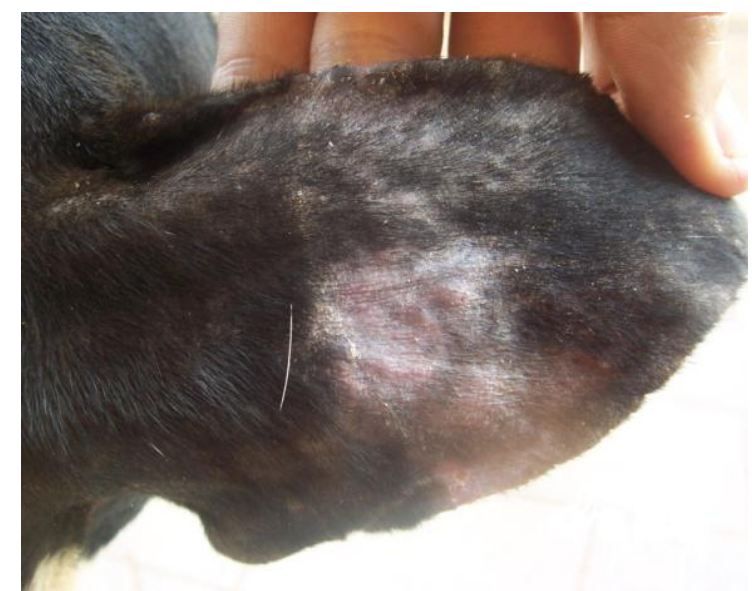

Figura 1. Lesões papulosas observadas na região dorsal da orelha direita de cão. Presença de alopecia.

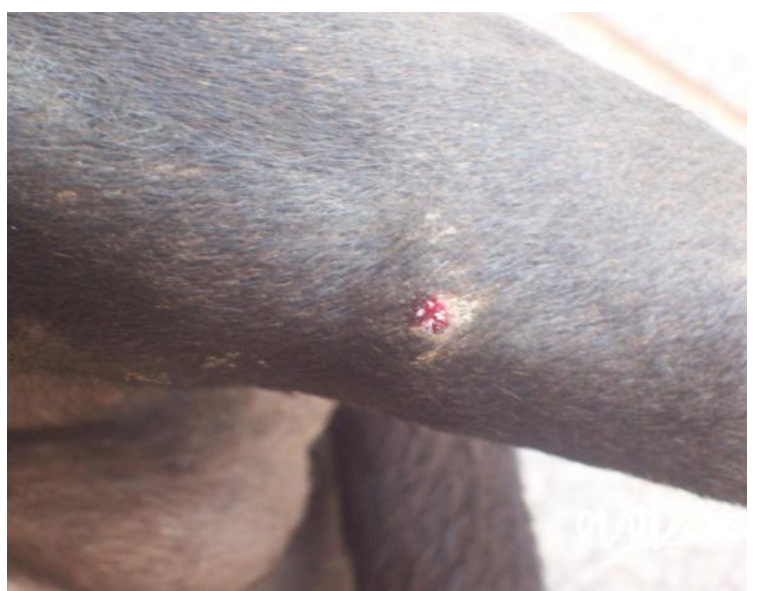

Figura 2. Lesão ulcerativa após rompimento de pápula no membro pélvico de cão.

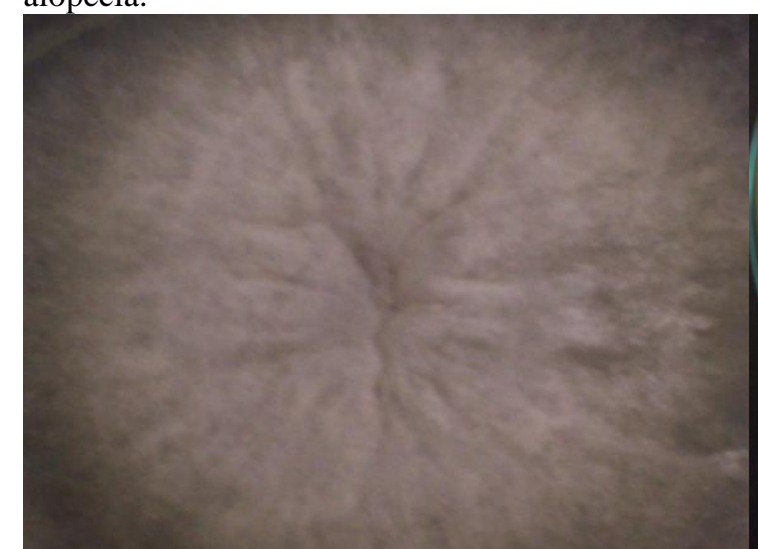

Figura 3. Anverso de colônia fúngica cotonosa em cão, branca acinzentada de Chaetomium spp.

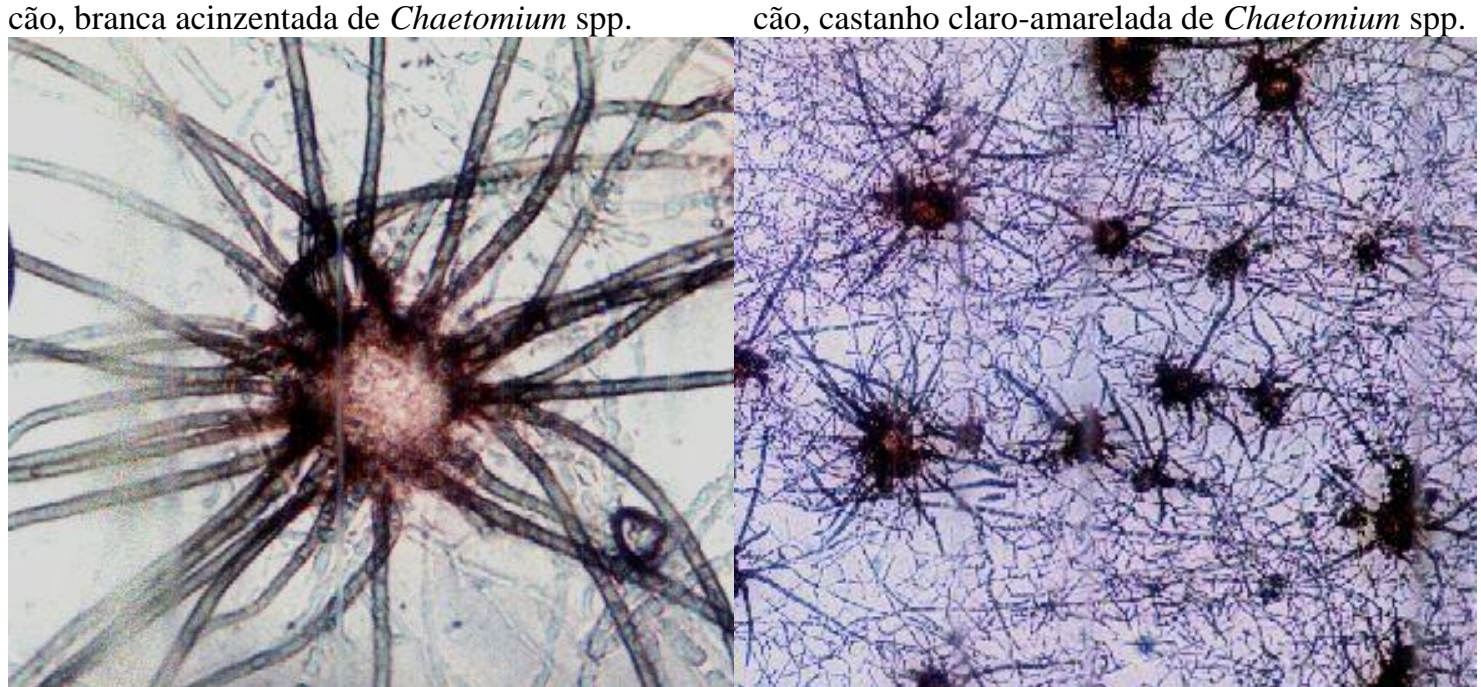

Figura 5. Peritécio negro, globoso, circundado por filamentos em forma de setas rígidas em cão. Aumento de 100x.

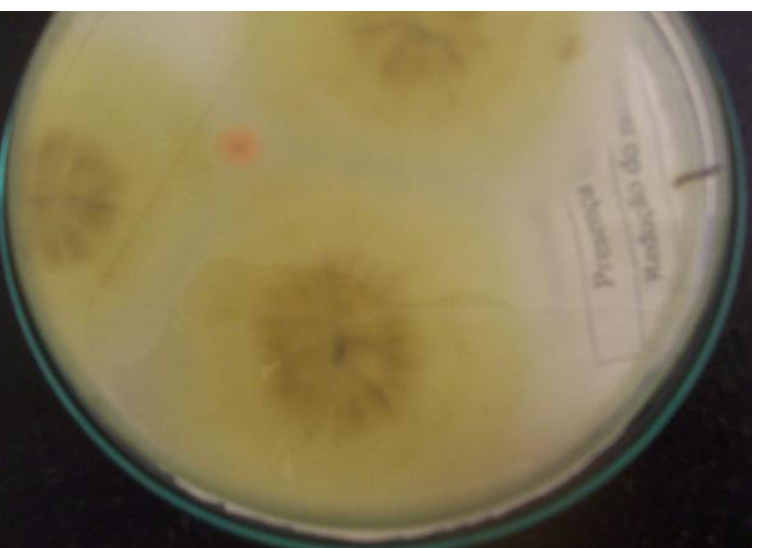

Figura 4. Reverso de colônia fúngica cotonosa em cão, castanho claro-amarelada de Chaetomium spp.

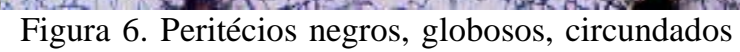
por filamentos em forma de setas rígidas em cão. Aumento de 40x. 


\section{REFERÊNCIAS}

AL-AIDAROOS, A.; BIN-HUSSAIN， I.; EL SOLH, H. et al. Chaetomium infection in two immunocompromised pediatric patients. Pediatr. Infec. Dis. J., v.26, p.456-458, 2007.

ALMEIDA, S.R. Apostila de micologia clínica. Universidade de São Paulo, 55p. Disponível em: $<$ http://www.portalbrasil.net/downloads/micoses. pdf $>$. Acessado em: 17 set. 2007.

ASPIROZ, C.; GENÉ, J.; REZUSTA, A. et al. Spanish case of onychomycosis caused by Chaetomium globosum. Med. Mycol., v.45, p.279-282, 2007.
LACAZ, C.S.; PORTO, E.; MARTINS, J.E.C. et al. Tratado de micologia médica Lacaz. São Paulo: Sarvier, 2002. p.527-528.

RODRIGUES-HEERKLOTZ, K.F.; PFENNING, L. Diversidade no reino Fungi: Ascomycota. 2007. Disponível em:

<http://www.biota.org.br/pdf/v1cap03.pdf>. Acessado em: 17 set. 2007.

SUTTON, D. A. Chaetomium spp. Disponível em:

<http://www.doctorfungus.org/thefungi/chaetomi um.htm>. Acessado em: 17 set. 2007. 